\title{
Clusters as a new management system of the Skadar Lake in Montenegro
}

\author{
Velenka Herbez*, and Alevtina Balakina \\ Moscow State University of Civil Engineering, Yaroslavskoe shosse, 26, Moscow, 129337, Russia
}

\begin{abstract}
Skadar Lake, located in Montenegro, is a valuable natural resource that combines a favorable climate, unique flora and fauna, as well as numerous cultural and historical monuments. For the sustainable development of the Skadar Lake, a new system of natural and human resources management is needed that corresponds to the cluster approach. An analysis determined the main components of tourist and recreational clusters necessary for the transition from the development of single territories with a tourist potential to the sustainable development of the whole territory of the Skadar Lake, creating a synergistic effect. The possibility of creating tourist and recreational clusters on the territory of the Skadar Lake in Montenegro, is considered as a system integrated into the national and local framework of strategic planning, increasing the viability of tourism and having a multiplier effect on it as well as related services. The analysis confirmed the need for a strategic and systematic approach in the sustainable development of Skadar Lake, and also emphasized the relevance of the cluster approach in the tourism development. Skadar Lake should be considered as a whole region and unique system of tourist and recreational cluster in order to create an efficient and flexible structure, which, within the framework of ecotourism and in accordance with the principles of sustainable development, will benefit both nature and visitors.
\end{abstract}

\section{Introduction}

The National Park Skadar Lake in Montenegro represents a unique combination of pure nature, diverse flora and fauna, cultural heritage, history and traditions of the local population. Two-thirds of Skadar Lake, the largest lake in the Balkans, belongs to Montenegro and one-third to Albania. The special value of this territory lies in its favorable climate and geographic position, thanks to which the best varieties of fruits and vegetables can be grown. In the villages on the territory of Skadar Lake, the main activities are agriculture, as well as wine and olive oil production. A steady increase in the number of tourist on the Skadar Lake territory has been observed and consequently the need for a new management strategy for mentioned valuable territory as well.

The main problems on the territory of Skadar Lake are: lack of environmental regulations, natural landscape degradation, reduction of traditional agricultural activities,

*Corresponding author: v.herbez@yahoo.com 
insufficient development of infrastructure facilities, a difficult economic situation in the region as well as unrealized natural and human potential.

The relevance of the topic is justified by the need for the development of tourist and recreational clusters in order to move from the development of single territories with a tourist potential to the sustainable development of the region's territory, creating a synergistic effect. The purpose of the study is to determine the relevance of the cluster approach. The objectives of the study are identification of the main components of tourism and recreation clusters as well as determination of the sustainable development principles. Solving these problems is a key stage in the further development of tourism activities on the territory of Skadar Lake.

\section{Methods}

In the 21 st century, there has been a tendency for a conscious and responsible attitude of tourists towards the natural environment, as well as the search for new types of tourist recreation in order to obtain new experiences [1]. The lack of experimental development and scientific base on Health, Educational and Recreational complexes in ecological settlements is one of the reasons for irrational nature management, difficulties in the territory development, problems of the existing settlement system, lagging in the economic development of small and medium-sized businesses [2]. It is proved around the world that in the conditions of the tourism market, clusters are the most efficient and flexible structures [3].

Cluster is understood as a geographically concentrated community that reinforces the competitive advantages of each other. Also they represent a new way of the economy [4], which is based on two principles - cooperation and competition. Furthermore cluster is considered as a special innovation environment and area of concentration of the "critical mass" of economic resources and information [5].

The necessity of a new management on the territory of Skadar Lake was observed, that should combine numerous sources such as human, natural, historical, etc. into a unique and sustainable system. On the territory of Skadar Lake, there are small villages, consisted of detached houses located at a short distance from each other or groups of houses combined into residential complexes whose main feature is compactness [6]. Some of the possible tourist activities on Skadar Lake are: cultural and educational activities, research, education, sports, fishing, excursions, traditional events, as well as different types of tourism: health, agricultural, religious, educational, recreational, etc. [7]. The main problem in the clusters development, on the territory of Skadar Lake as well as other regions, is the lack of a full-fledged statistical base in the field of tourism and the flawed methodology for forming clusters [8].

The complexity of the tourist cluster analysis is explained by the lack of guidelines and the complexity of tourism is explained as a socio-economic phenomenon [9]. The uniqueness of natural resources, local traditions and culture of recreation influence the tourist cluster specifics as well as, the process of its formation and the definition of the main tourist products [10]. Clusters need to be fostered by special policy and measures that will help establishment of professional management, long-termed budget, higher involvement and proactive behaviour of rural tourism businesses. In line with this, the role of the state should be pointed out with special focus on: dissemination of information about opportunities generated by cluster creation, support for public-private and private-private cooperation, creation of a favourable business environment and infrastructure base that could facilitate business success, and provision of education and training opportunities [11]. 


\section{Results}

Considered tourist and recreational clusters are located in: the USA (Napa Valley), Australia (Queensland), Russia (Veliky Novgorod, Winter Olympics clusters in Sochi, Samara region), South Africa, Spain, Turkey, France, Mexico and Indonesia. Although these clusters differ in geographic scale, structure and level of development, they are united by a relationship of trust, which is the basis for regions promotion in the domestic and international markets. Also, a common feature of the clusters is the decisive role of the state and public-private partnership.

In the course of the analysis, the starting conditions for the formation of a tourist cluster were identified: undeveloped tourism industry, migration of the local population, intensifying competition from other tourist areas, increase in tourist flows, etc. Main components were determined based on the analysis of the world experience in the development of tourist and recreational clusters (see Fig. 1):

1.Object of tourist interest (attractions, events, restaurants, tourist accommodation and transport);

2.Supporting industries (local goods and services, local transportation, craft and banking, marketing agencies, product suppliers, real estate services, maintenance and equipment suppliers);

3.State and private institutions (government agencies, local tourism organizations, educational and research institutions, industry institutions);

4. Related industries (medical services and food cluster).

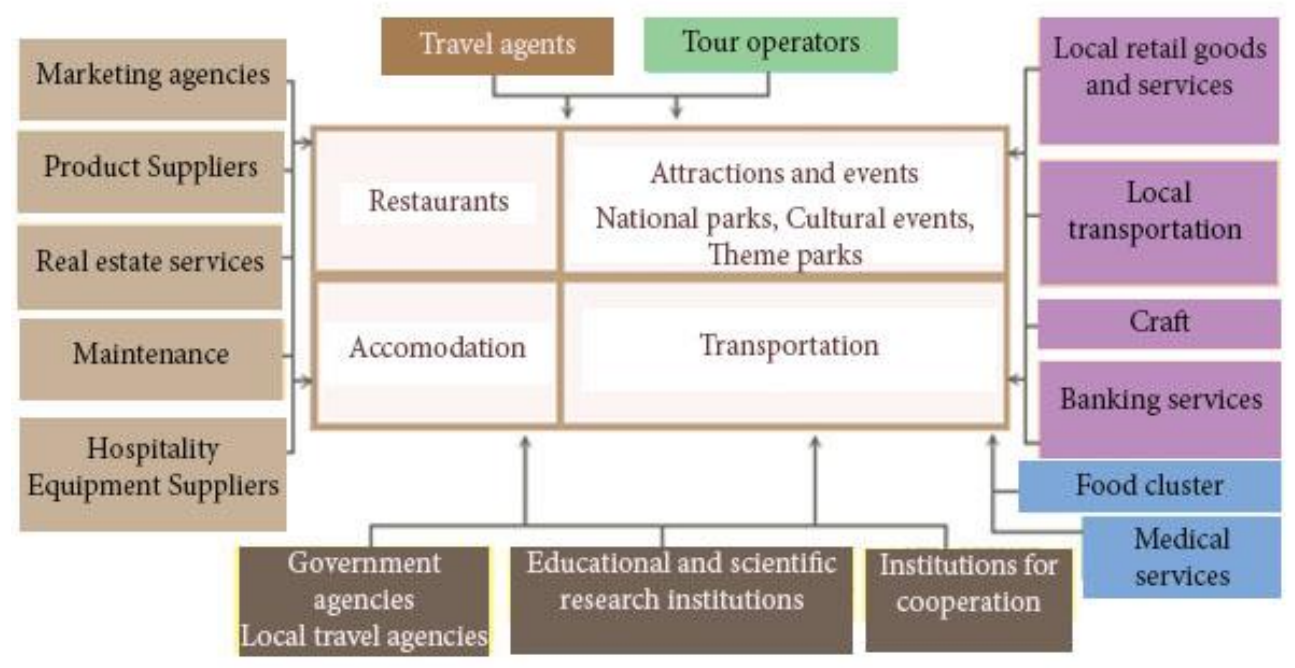

Fig. 1. The main components of the cluster.

In the process of tourist and recreational clusters analysis, the following stages in the process of cluster development were identified: forming a management group from representatives of interested organizations, determining a development strategy, seminars and meetings with local residents, tourism industry workers and politicians as well as marketing. Natural, climatic, social, economic and political conditions were determined as basic conditions on which depends an internal complex structure of the cluster. The relationship between the related services, determining the core of the cluster as well as the relationship between public and private institutions determines the formation of a tourist and recreational cluster. 
Clusters are defined as points of tourism infrastructure growth and development, that activate small and medium-sized businesses around them, providing an intensive increase in domestic and inbound tourist flows, as well as a multiplier effect on the development of related services and local economy.

\section{Discussion}

The analysis confirmed the relevance of the cluster approach in the development of the field of recreation and travel. The results of the analysis can be applied in the future development of tourist and recreational clusters on the Skadar Lake territory.

Currently, most of the prerequisites for creating clusters are insufficiently developed. First, it is necessary to create public-private partnerships and to involve all stakeholders in order to create competiveness. Secondly, it is necessary to conduct research and clearly define the strategy for the development of tourist and recreational clusters on the territory of Skadar Lake, taking into account existing cultural and historical environment. It is also important to maintain traditional activities, to provide organized retail and a variety of specialized services for tourists. Particular attention should be paid to: developing new types of tourist accommodation built in harmony with nature, as well as a variety of cultural activities and sustainable transport modes.

There are basic conditions for the development of thematic clusters along the Skadar Lake basin (see Fig. 2), such as: agrarian, historical, cultural, educational, recreational, etc.

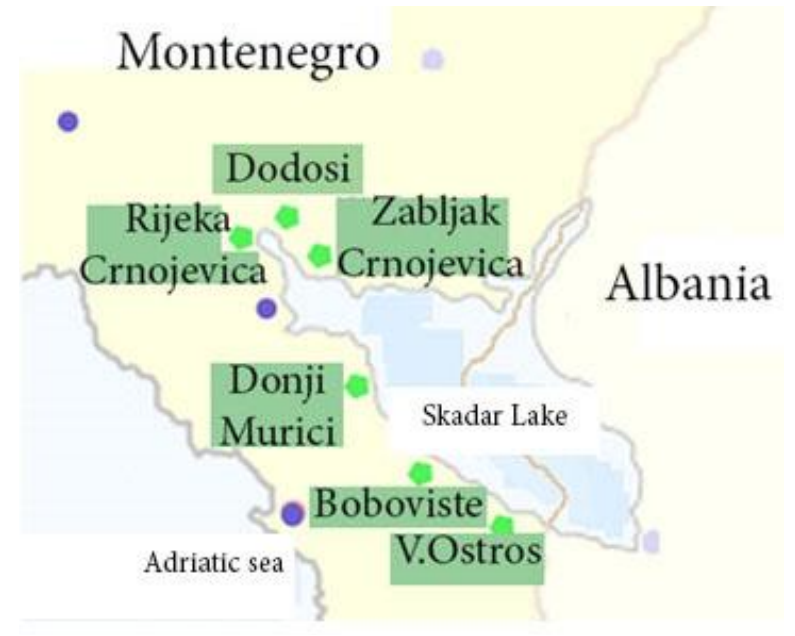

Fig. 2. Clusters locations are indicated.

Unique nature, flora and fauna, a variety of agricultural activities, as well as historical and cultural heritage are expected to become the tourist core of clusters that will be managed by public-private partnerships. Involvement of the local population in tourism activities and creation of a sustainable cluster system are the first steps towards solving the problems of the seasonality of tourism on Skadar Lake and reducing the trend of migration to large cities.

\section{Conclusions}

Practice has shown that clusters are the most effective system of management and development of regions with a tourist potential. In order to provide sustainable tourism 
development, clusters need to be fostered by policies and measures aimed at establishment of professional management, long-termed budget, quality standards implementation, higher involvement and proactive behaviour of local people, businesses, tourist organisations etc. Consequently, the role of the state should be pointed out, as well as the role of related stakeholders such as educational institutions, media, tourism and food industry, medical services etc.

Tourist and recreational clusters are relatively new phenomenon in Montenegro. Therefore it is important to consider Skadar Lake as a whole region with a tourist potential and to create a unique and sustainable model that will benefit both nature and the visitors. Although at the moment the most prerequisites for tourist and recreational clusters on the territory of Skadar Lake are not developed, it is expected that cluster approach will all resources and that the potential of Skadar Lake will be revealed.

Creation of successful tourist and recreational clusters on Skadar Lake should start from the comprehension of already established cultural and historical environment, favorable climate and geographical position, taking into account economic, environmental and social factors. The development of tourist and recreational clusters on Skadar Lake could contribute to the revival of cultural values, the protection and restoration of historical heritage, as well as the improvement of the local economy. Also it could help in creation of sustainable connection between people and nature, in order to make new experiences and protect the environment.

Tourist and recreational clusters on Skadar Lake would imply visitors active time in nature, not only using recreational opportunities, but also taking into account their preservation. The development of tourism and recreation clusters integrated into national and local strategic planning frameworks can increase the long-term viability of tourism in Montenegro as well as maximizes the positive effects of tourism development while minimizing the negative.

\section{References}

1. R. Sharpley, J.Econ., 5, 7-22 (2006)

2. A.E. Balakina, I.V. Dunichkin, O.A. Kochanov, A.A. Zolotarev, Bull. MGSU,1-2, 3038 (2011)

3. L.R. Maklashina, C.Econ., 5, 116-120 (2012)

4. A.P. Myamlin, Prob.Mod.Econ., 2, 230-232 (2013)

5. S.F. Pyatinkin, T.P. Bykova, Int.C.Sci.Tech.Inf., 13-19, (2008)

6. P. Babic, K. Vuksanovic, Spatial plan for a special purpose, Skadar Lake National Park, 281 (2018)

7. D. Vuksanovic, S. Popovic, Architectural Atlas of Montenegro, 36 (2006)

8. L.B. Shabanova, R.A. Grigoriev, SNOTRD, 1-2, 163-170 (2014)

9. L.K. Gurieva, Reg.Econ.Theor.Prac., 22, 72-80 (2009)

10. A.E. Boyko, PMER, 2, 224-228 (2009)

11. I.Maric, Buss.Sys.Res. 4, 94-107 (2013)

12. I.G. Kazaryanz, I.A. Eremenko, M.A. Tkachenko, A.V. Suhovenko, Eur.Res.Stud.J, 21, 167-177 (2018)

13. E.J.Michael, SAGE, 9, 133-145 (2013)

14. L.N. Kazmina, V.S. Makarenko, V.V. Provotorina, T.N.Grigorenko, Int.J.Ecc.Bus.Admin., 7, 510-520 (2019) 
15. X.Li, SAGE J., 15 (2019)

16. E.J. Michael, Tour.Manag., 23, 117-125 (2002)

17. M.Boiko, M. Bosovska, N. Vedmid, S. Melnychenko, A. Okhrimenko, Probl.Persp.Manag., 15, 134-149 (2017)

18. D.D.Fundeanu, Proc.Ecc.Financ., 23, 744-749 (2015)

19. O.A. Fetisova, V.V. Kurchenkov, E.S. Matina, Medit.J.Soc.Sci., 6, 142-150 (2015)

20. I.Maric, Tour., 17, 84-95 (2013) 